\title{
Keratoconus: an inflammatory disorder?
}

V Galvis ${ }^{1,2}$, T Sherwin ${ }^{3}$, A Tello ${ }^{1,2}$, J Merayo ${ }^{4}$, R Barrera ${ }^{1}$ and A Acera ${ }^{5}$

\begin{abstract}
Keratoconus has been classically defined as a progressive, non-inflammatory condition, which produces a thinning and steepening of the cornea. Its pathophysiological mechanisms have been investigated for a long time. Both genetic and environmental factors have been associated with the disease. Recent studies have shown a significant role of proteolytic enzymes, cytokines, and free radicals; therefore, although keratoconus does not meet all the classic criteria for an inflammatory disease, the lack of inflammation has been questioned. The majority of studies in the tears of patients with keratoconus have found increased levels of interleukin-6 (IL-6), tumor necrosis factor- $\alpha$ (TNF- $\alpha$ ), and matrix metalloproteinase (MMP)-9. Eye rubbing, a proven risk factor for keratoconus, has been also shown recently to increase the tear levels of MMP-13, IL-6, and TNF- $\alpha$. In the tear fluid of patients with ocular rosacea, IL-1 $\alpha$ and MMP-9 have been reported to be significantly elevated, and cases of inferior corneal thinning, resembling keratoconus, have been reported. We performed a literature review of published biochemical changes in keratoconus that would support that this could be, at least in part, an inflammatory condition.
\end{abstract}

Eye (2015) 29, 843-859; doi:10.1038/eye.2015.63; published online 1 May 2015

\section{Introduction}

Keratoconus is a clinical term used to describe a state of the cornea derived from its focal thinning and protrusion, which eventually may lead to a conical shape. It is a bilateral and asymmetric condition frequently characterized by a progressive evolution. Keratoconus has been classically defined as a non-inflammatory disorder due to the lack of neovascularization and cellular infiltration; ${ }^{1,2}$ however, as Davidson et $a l^{3}$ mentioned in a recent review the etiology of keratoconus is not still completely understood. Association between atopy and keratoconus has been identified for more than 50 years, but multiple studies have shown conflicting results. ${ }^{4-8}$ Higher levels of serum immunoglobulin E was found in 59\% of keratoconus patients in studies performed around 30 years ago. 9,10

However, as many of the patients with ocular allergic diseases rub their eyes excessively, it remained unclear whether atopy itself or eye rubbing was the factor related to keratoconus. Harrison et al ${ }^{6}$ found that in atopic keratoconus patients, the disease occurred more frequently on the side of the dominant hand. More recently, in 2000, Bawazeer et al ${ }^{11}$ published their results of a case-control study, which showed in the univariate associations that there was an association between keratoconus and atopy, as well as eye rubbing and family history of keratoconus. However, in the multivariate analysis, they found that only eye rubbing was still a significant predictor of keratoconus. They concluded that atopy may contribute to keratoconus but most probably via eye rubbing associated with the irritation of atopy. ${ }^{11}$

More than 20 years ago, enzymatic alterations ${ }^{12-14}$ and alterations in interleukin (IL)-1 receptors density were detected. ${ }^{15,16}$ Pouliquen et $a l^{17}$ in 1996 had suggested that modulation of the degradation of the extracellular matrix might involve inflammatory cytokines and enzymes by either primary or secondary mechanisms. More recent studies have proved significant action of inflammatory mediators and a possible effect of oxidative stress, thus questioning the noninflammatory status of the disease. ${ }^{3,18-25}$

In 2002, Tachibana et al $2^{26,27}$ reported that they established an inbred line of spontaneous mutant mice with keratoconus-affected corneas (SKC mice) resembling corneas of human eyes with keratoconus, but which were often associated with a red punctum at the apex.. They found that the red puncta seen in the center of the corneas were due to vascular infiltration and extravasations of blood cells, and the corneas showed lymphocyte infiltration. They suggested
${ }^{1}$ Centro Oftalmologico Virgilio Galvis, Floridablanca, Colombia

${ }^{2}$ Faculty of Health Sciences, Universidad Autonoma de Bucaramanga,

Floridablanca, Colombia

${ }^{3}$ Faculty of Medical and Health Sciences,

Department of Ophthalmology, New Zealand National Eye Centre, University of Auckland, Auckland, New Zealand

${ }^{4}$ Instituto Oftalmologico Fernandez-Vega, Oviedo, Spain

${ }^{5}$ Bioftalmik Applied Research, Derio, Spain

Correspondence:

Dr V Galvis, Centro Medico Ardila Lulle, Piso 3, Modulo 7. Floridablanca, Santander, Colombia

Tel: +57 7 6392929;

Fax: +5776392626

E-mail: virgiliogalvis@ gmail.com

Received: 31 August 2014 Accepted: 8 March 2015 Published online:

1 May 2015 
that inflammation could be also related at least with some subtype of human keratoconus. Vascular infiltration of the keratoconic cornea of a patient with a mutation of the VSX1 gene has been reported. ${ }^{28}$

In keratoconus, genetic factors appear to be multifactorial and have been considered fundamental to the etiology and progression of keratoconus, but does not explain a vast majority of the cases. Environmental factors, such as eye rubbing and rigid contact lens wear, have been linked with the condition. Recently, keratoconic corneas and tears from patients with the disease have been found to have elevated levels of proinflamamatory cytokines, accumulation of cytotoxic byproducts from the nitric oxide (NO) and lipid peroxidation pathways, abnormal antioxidant enzymes, and increased levels of mitochondrial DNA damage.

We will review the different aspects of this complex disease, for which etiopathogenesis remains a mystery for the most part.

\section{Epidemiology}

Published epidemiologic reports document a wide prevalence range, probably explained by differences in geographical situation, populations studied, and diagnostic criteria used in the investigations. Rates as low as 0.3 per 100000 people $(0.0003 \%)$ in Russia and as high as $2.3 \%$ in India, $2.34 \%$ in Israel, and 2500 per 100000 $(2.5 \%)$ in Iran ${ }^{8,29-31}$ have been published. In the Indian study, the criterion for keratoconus diagnosis was a corneal refractive power $\geqslant 48 \mathrm{D}$, using keratometry, which most probably diminished the specificity of the research. ${ }^{30}$ However, recently another group of researchers from Iran, using clinical examination (retinoscopy and slit lamp examination) and topography (TMS-4 and Orbscan II) reported a similar prevalence of keratoconus among college students (2500 per 100 00, ie, $2.5 \%$ ), which supports the possibility of a very high prevalence in some Asiatic countries. ${ }^{31}$

The prevalence cited by most of the studies was determined by Kennedy et $a^{32}$ in Minnesota, USA, and is equal to 54.5 per 100000 population. That study retrospectively analyzed medical charts of patients diagnosed during the period 1935 through 1982 by ophthalmologists, using keratometry (irregular mires) and retinoscopy (irregular light reflexes). ${ }^{32}$ Currently, it is known that many mild keratoconus cases will not show the typical findings of irregularity of the light reflexes in retinoscopy or irregularity in keratoscopic mires, and moreover many of those patients with mild keratoconus may never visit an ophthalmologist, all of which would cause that the prevalence determined by Kennedy et $a l^{32}$ most probably underestimated the frequency of the condition. As previously indicated, much higher prevalences have been recently reported in Asian populations. ${ }^{30,31}$

The disease has been shown to be more prevalent also in patients searching for refractive surgery, as a consequence of self-selection bias, due to their refractive error. ${ }^{33-37}$ A study in Colombia reported 3.9\% prevalence in a group of patients that underwent an ophthalmic evaluation in a refractive surgery center. ${ }^{37}$ In Yemen, prevalences of $15.5 \%$ of keratoconus and $9.4 \%$ of forme fruste keratoconus were found among refractive surgery candidates. ${ }^{33}$ In a study in the United States, $25.5 \%$ of eyes evaluated for refractive surgery met the Rabinowitz criteria for keratoconus suspect. ${ }^{34}$

A vast majority of the studies state that the age of onset of the disease is between 20 and 30 years. Some studies report a higher prevalence in male patients, whereas others indicate that there is no significant difference between genders. ${ }^{32,38}$ Race, on the other hand, seems to be an important risk factor as previously indicated. Asians (people from India, Pakistan, and Bangladesh) have prevalence 4.4-7.5 higher than Caucasians. ${ }^{39,40}$ Others authors have suggested that differences in exposition to ultraviolet light, according to latitude in the terrestrial globe could explain differences in prevalence according to geographical localization. ${ }^{41}$

\section{Genetics}

There is wide evidence of the genetic component of the condition, which might explain its bilateralism, its association with diseases such as Down syndrome, Apert syndrome, Crouzon syndrome, Angelman syndrome, Noonan syndrome, Leber's congenital amaurosis, EhlersDanlos syndrome, Granular corneal dystrophy, Osteogenesis imperfecta, and Mitral valve prolapse. ${ }^{42-44}$ Genetics would also explain the apparent autosomal dominant pattern of inheritance found in certain families, the higher prevalence for the disease in families with one affected individual, and the high concordance among monozygotic twins. ${ }^{45-48}$

Burdon et al $^{48}$ found a Mendelian inheritance pattern in an Australian family. On the other hand, consanguinity have been associated with a higher risk of development of keratoconus. ${ }^{39,49}$ Recently, Kriszt et al ${ }^{50}$ performed a segregation analysis of 60 unrelated sporadic keratoconus families and suggested that this type of keratoconus is a complex non-Mendelian disease. However, genetics does not seem to be the only factor in keratoconus, and as many researchers have suggested it is very probable that the vast majority of cases are the result of patients exhibiting genetic predisposition triggered by environmental factors. ${ }^{3}$

An important number of locations for genes on chromosomes (loci), 17 of them until now, have been 
related to keratoconus, thus showing genetic heterogeneity rather than a single major gene effect responsible for development and progression of the disease. $^{51,52}$ Some of the genes with reported mutations are SOD1 (locus 21q22.11), VSX1 (locus 20p11.2), and DOCK9 (locus 13q32), which regulate the expression of superoxide dismutase (SOD), photoreceptor cells, and G protein, respectively. ${ }^{53-55}$ Recently, mutations in MIR184 have been identified as an uncommon cause of keratoconus. ${ }^{55,56}$ LOX (locus 5q23.2), the gene encoding lysyl oxidase (LOX) enzyme, which is involved in collagen and elastin cross-linking, have also been related to keratoconus. ${ }^{57}$

Association between single-nucleotide polymorphisms in the hepatocyte growth factor (HGF) gene and keratoconus has been found. ${ }^{58,59}$

Multiple studies have reported a statistically significant risk of developing keratoconus in patients with polymorphism of the gene in charge of the IL- $1 \beta$ coding (IL-1B-31 T > C and IL-1B-511 C > T); ${ }^{60,61}$ nevertheless, a recent study in a different population found no clear relation between the $I L-1 B$ gene polymorphism and the receptor antagonist IL-1 (ILRN VNTR) with the possibility of keratoconus development. ${ }^{62}$

In vitro studies have found that cultured keratoconus corneal fibroblasts exhibit increased basal generation of reactive oxygen species (ROS) and reactive nitrogen species (RNS). In addition, they were more susceptible to oxidative challenges than normal fibroblasts. The accumulation of ROS/RNS can initiate a vicious cycle of damage to the mitochondrial DNA (mtDNA), which eventually will cause dysfunction of those organelles, decreased oxidative phosphorylation and additional increase of ROS/RNS production. Normally, $4 \%-5 \%$ of the consumed mitochondrial oxygen is transformed to superoxides and $\mathrm{H}_{2} \mathrm{O}_{2}$, which are usually eliminated by antioxidant enzymes. However, in keratoconic corneas many of those antioxidant enzymes are abnormal. Thus, mitochondria may have a dual role as a major source and a target for ROS/RNS. Recent studies have shown that keratoconic corneas have increased levels of mtDNA mutations compared with controls. ${ }^{63-66}$ In addition, it has been also established that the mean relative mtDNA content is higher in patients with the disease. ${ }^{67}$

Genetics of keratoconus has been recently extensively reviewed by Abu-Amero et al. ${ }^{52}$

\section{Perspectives}

As cited by Grzybowski and McGhee, ${ }^{68}$ in 1859 Nottingham published a detailed description of keratoconus and various classical characteristics of it in his piece 'Practical observations on the conical cornea and on the short sight and other defects of the vision connected with it', based on the cases he had observed with a conical cornea; however, during the last 150 years a complete understanding of this disease has not been reached and its origin remains as an unsolved issue to the present time (i.e., 2014). ${ }^{3,69}$ According to scientific evidence collected in recent decades, the condition is likely to be a multifactorial, multigenic disorder with complex inheritance patterns, probably triggered by environmental factors: a 'two-hit' hypothesis. As many proinflammatory mediators have been associated with keratoconus during the last two decades, a genetic predisposition to abnormalities of any of those inflammatory components initiated by external factors (eye rubbing, contact lenses, or exposure to ultraviolet light) may constitute the origin of the disease, as suggested by Kenney et $a l^{73}$, and then for several other researchers. As recently proposed by McMonnies ${ }^{71}$, in concordance with that hypothesis, epigenetics (heritable traits not caused by changes in the DNA sequence, but in gene expression) seems to have an important role in this complex disease etiology. 3,70-73

Considering all these concepts, the inflammatory nature of the condition (suggested by the findings of proinflamatory cytokines increase and disturbance in oxygen reactive species elimination by scavenging system) may be plausible.

\section{Materials and methods}

For this review, we searched PubMed database without restriction of language, for articles related to keratoconus. Using the 'Advanced search builder' tool, the terms 'keratoconus', 'corneal ectasia', and 'pellucid marginal degeneration' were combined with the terms 'aetiology', 'pathophysiology', 'antioxidants', 'extracellular matrix enzymes', 'oxidative stress', and 'inflammation' included in the title or the abstract of the articles. Papers published up to December 2014 were included. There were no restrictions on the basis of date or language of publication.

All articles were carefully reviewed, to select those that reported findings on pathophysiology of the condition. References cited by these papers were also retrieved and analyzed.

In total, we found 342 articles, but finally we selected from them and their list of references, 166 articles.

In addition, we used a web search engine (Google) using the following terms: 'keratoconus', 'corneal ectasia', and 'pellucid marginal degeneration' combined with the terms 'aetiology', 'pathophysiology', 'antioxidants', 'extracellular matrix enzymes', 'oxidative stress', and 'inflammation', to find other publications (books or chapters) on the topic. We reviewed four chapters of two recently published books. 


\section{Pathophysiology}

Keratoconus is a complex disorder. Recent technological advances have enabled more sophisticated molecular studies of the keratoconic condition, which changed some of the previously conceived theories for its pathogenesis. ${ }^{3,24,25,73-76}$

Pathophysiologic components of keratoconus can be largely classified into the following: alterations of the stroma composition, imbalance of pro-inflammatory and anti-inflammatory molecules, imbalance of the enzymes that cause extracellular matrix degradation and their corresponding inhibitors, oxidative stress, and cellular hypersensitivity. These events occur simultaneously and may present positive feedback between one another. Even though there is causality between them, it is yet unclear which precedes the other and which events are necessary for the evolution of the disease.

\section{Corneal stroma composition}

Collagen is the main component of cornea. Variations in quantity, disposition, or morphology of this protein will drastically alter the cornea's architecture. There are over 21 types of collagen in the human body; however, type I corresponds to $75 \%$ of the amount present in the cornea, ${ }^{77}$ although cornea also contains collagen types III, V, and VI regularly interwoven into lamellae, and collagen type XII in epithelium basement membrane and sub-epithelial stroma. ${ }^{74,78}$ Although the reduction in the number of lamellae within the affected region could correspond simply to a redistribution of the collagen within the cornea by slippage between the lamellae, as suggested by Polack $^{79}$ almost 40 years ago, this explanation by itself does not seem to be enough to account for the stromal thinning, especially in light of more recent studies showing that the collagen lamellae in keratoconus corneas exhibit a significant decrease in number compared with controls, ${ }^{80}$ and that keratoconus diminishes the amount of types I, III, V, and XII collagen, as well as lumican and keratocan proteins, as determined using highly sensitive mass spectrometric analysis. ${ }^{78}$ Additional researchers have reported the reduction of the interfibrillar distance of collagen sheets and the increase of proteoglycans with abnormalities in their configuration as the condition evolves. These changes allow more contact between the collagen sheets and the proteoglycans, thus altering the stroma organization where alterations in interlamellar proteoglycans might contribute to slippage of the lamellae. ${ }^{81}$ Meek et al, ${ }^{82}$ using synchrotron X-ray scattering patterns, confirmed that a gross rearrangement of vertical and horizontal collagen lamellae occurs in keratoconus. Tissue degradation alone does not account for that systematic realignment of fibrils, and so the authors suggested that both slippage and remodeling have a role. Morishige et al, ${ }^{83}$ using second-harmonic imaging, identified less lamellar interweaving and a marked reduction or loss of lamellae inserting into Bowman's layer in corneas with keratoconus.

In addition, fibronectin and tenascin, were detected in the anterior portion of keratoconic corneas, while those glycoprotein were not found in the anterior portion of normal or scarred corneas. ${ }^{84}$ There is also a report of an increase in type IX collagen and a dysregulation in type XVIII collagen expression posterior to the healing process in patients with keratoconus. ${ }^{85}$

Cheung et al, ${ }^{74,86}$ analyzing ex vivo the modulation of the healing process of corneas with keratoconus and of non-keratoconic corneas, found that fibroblast growth factor 2 (FGF-2), platelet-derived growth factor (PDGF), and epidermal growth factor (EGF) were found to be upregulated in keratoconic corneas in comparison with normal uninjured corneas, but following an ex vivo secondary injury EGF, FGF-2, and PDGF were found to be downregulated in both non-keratoconic and keratoconic corneas, but they were decreased further in the later ones (FGF-2 was reduced to undetectable levels). According to those results, the authors concluded that dysregulation of reparative pathways in keratoconus causes on the one hand keratoconic corneas to appear in a perpetually injured state, but on the other hand they also produce a weakened repair response to a secondary lesion (eg, eye rubbing or contact lens wear and oxidative damage), which further supported what the authors had previously postulated: that underlying abnormalities in stromal repair and activities linked to oxygen reactive species along with the interaction between these phenomena were implicated in the development of keratoconus. ${ }^{74,86}$

\section{Inflammation}

ILs are secreted proteins and signaling molecules (cytokines), which function as important mediators of immune responses, cell proliferation, and inflammatory reactions. ${ }^{87,88}$ As early as 1991, Girard et al ${ }^{89}$ found that two cytokines, transforming growth factor- $\beta$ (TGF $\beta$ ) and IL-1, modulated the expression of metalloproteinases by cultured corneal stromal cells. In corneal buttons using immunofluorescence staining, Zhou et $\mathrm{al}^{90}$ found that the expression of TGF $\beta$, IL- 1 , vimentin, and tenascin was enhanced in keratoconus corneas.

According to the findings of an experimental study on cell cultures of keratocytes from normal corneas and from corneas with keratoconus, Pouliquen et a ${ }^{17}$ suggested that cytokines, IL-1, tumor necrosis factor- $\alpha$ (TNF- $\alpha$ ), TGF $\beta$, IL-6, IL-8, and PDGF, might regulate a protease cascade involving the plasmin system (including: tissue plasminogen activator (t-PA), urokinase-type 
plasminogen activator (u-PA), and plasminogen activator inhibitor), cyclooxygenase, and metalloproteinases, which eventually would lead to the observed changes in the extracellular matrix of the cornea with keratoconus. These researchers found that the kinetics of cyclooxygenase, which converts arachidonic acid into prostaglandin E2 (PGE2) was significantly increased in keratocytes from keratoconus (a 10-fold increase in the maximum reaction rate $\left.\left(V_{\max }\right)\right)$, and that the basal PGE2 production was 10 times greater than in keratocytes from normal corneas. In addition, the ketatoconic cells exhibited a very strong effect of t-PA and u-PA on the secretion of PGE2 (Pouliquen et al ${ }^{17}$ ). PGE2 has been related to antifibrotic effects via inhibition of major pathobiologic functions of effector fibroblasts including chemotaxis, proliferation, collagen synthesis, and differentiation to myofibroblasts. ${ }^{91}$

Dogru et al ${ }^{92}$ found that corneal sensitivity was significantly lower in keratoconus patients compared with controls, especially in patients with severe keratoconus. They also found tear film break-up time values shorter in moderate and severe keratoconus, and fluorescein and rose bengal scores significantly higher in keratoconus patients. Using conjunctival impression cytology, they found prominent squamous metaplasia and goblet cell loss in keratoconus patients. The authors proposed that keratoconus might have, at least in part, an epithelial origin, which would explain the concurrent conjunctival involvement. ${ }^{92}$

More recently, it has been proved in vivo, studying proteins present in tears, that there is an abnormal production of ILs in keratoconus, as reported by several research groups. Lema et $a l^{21}$ published that the tear film in keratoconus showed increased levels of proinflammatory cytokines IL-6, TNF- $\alpha$, and also higher levels of matrix metalloproteinase 9 (MMP-9). The same group of authors reported in 2009 that in patients with unilateral keratoconus and the contralateral eye having subclinical disease, IL- 6 and TNF- $\alpha$ levels were increased in both eyes but only TNF- $\alpha$ was significantly higher in the keratoconic eye. Increased MMP-9 levels were found in keratoconic eyes only. ${ }^{22}$

Lema $e^{2} \mathrm{al}^{20}$ found that intercellular adhesion molecule 1 (ICAM-1), vascular adhesion molecule 1 (VCAM-1), IL-6, and MMP-9 were overexpressed by 2-40 times, whereas anti-inflammatory marker IL-10 was expressed 8 times less in keratoconic patients who wore contact lenses compared with normal myopic subjects. ICAM-1 has been shown to participate in corneal inflammation. ${ }^{74}$ Lema et $a l^{20}$ concluded that a higher level of inflammatory response to contact lens wearing was present in keratoconus in comparison with normal corneas.

Using antibody-based techniques, Balasubramanian et al in $2012^{18}$ reported findings consistent with those shown by Lema et $a l^{20}$ with increased tear expression of MMP-1, - -3, -7, and -13, IL-4, -5, -6, and -8 , and TNF- $\alpha$ and $\beta$ in keratoconus. ${ }^{10}$ Previously Pannebaker et $a l^{93}$ had also found increased levels of active MMP-1 in keratoconus patients and Seppälä et $a l^{94}$ have reported that MMP-1 were upregulated in keratoconic corneal specimens.

Although Balasubramanian et al ${ }^{18}$ found higher levels of MMP-9 in tears from keratoconic eyes, the difference was not statistically significant. They indicated that the mismatch between their results and the ones obtained by Lema et al, ${ }^{21}$ who reported increased levels of MMP-9, might be explained, because they used antibodies to the active MMP-9, while Lema et al did not. Recently, Balasubramanian et al ${ }^{95}$ used an electrophoretic device to partition tear proteins and enrich for the low mass $(<25 \mathrm{kDa})$ proteins and peptides present in low-volume complex samples, followed by linear ion trap quadrupole Fourier transform mass spectrometry, and used spectral counting for the quantitative comparison of proteins between tears from eyes with keratoconus and normal subjects. They found a relative increase in the abundance levels of cathepsin B and decreased levels of polymeric immunoglobulin receptor, $\alpha$-fibrinogen, cystatin $\mathrm{SN}$, and cystatin $S$ in the tears of subjects with keratoconus, meaning that tear proteins differentially expressed in keratoconus included increased proteases and decreased protease inhibitors. ${ }^{95}$ The findings of a lower level of cystatins by Balasubramanian et al ${ }^{95}$ confirmed the ones previously reported in 2011 by Acera et al, ${ }^{96}$ who compared tears from 12 normal subjects and 12 patients with keratoconus, using two-dimensional gel electrophoresis and liquid chromatography-mass spectrometry, and found a significant decrease in the levels of members of the cystatin family in keratoconus patients. Cystatins are inhibitors of cysteine proteases, also known as thiol proteases, which are enzymes that degrade proteins. Cysteine proteases are commonly encountered in fruits (papaya, fig, kiwifruit, and among others) and latices of different plant families are known to contain those enzymes. ${ }^{97}$ In fact, they are the active ingredients of meat tenderizers. ${ }^{98}$ Cystatins, inhibitors of those proteolitic enzymes, are divided into type 1 known as intracellular (A and $\mathrm{B}$ ), type 2 known as extracellular (C, D, E/M, F, G, S, SN, and SA) and type 3 known as intravascular (L- and H-kininogen). ${ }^{99,100}$ The decreased levels of cystatins found in tears from eyes with keratoconus could be a sign of an increase in the degradation of tear proteins, which would be correlated with the decrease in the concentration of total protein in tears from keratoconus patients found by Acera et al. ${ }^{96}$

In concordance with findings by Balasubramanian et $a l^{95}$ in tears, lysosomal cathepsin B and cathepsin G have been found to be elevated in keratocytes of keratoconic corneas, localized beneath compromised 
regions of Bowman's layer and the stroma of morphologically compromised regions, compared with normal tissue. ${ }^{101}$

Jun et a ${ }^{103}$ evaluated Type- 1 helper $\mathrm{T}$ cell cytokines (IL-12, IFN- $\gamma$, and TNF- $\alpha$ ), Type-2 helper T cell cytokines (IL-4, IL-10, and IL-13), and T-helper 17 cell cytokines (IL-17) in serum and tears of patients with keratoconus, to determine whether an altered inflammatory response can contribute to the keratoconus etiology or not. There were low levels of cytokines in blood, with no significant differences between the groups, thus suggesting a dissociation between the condition and systemic inflammation. In agreement with previous results Jun et $a l^{103}$ found higher levels of IL-6 in the tear film samples of keratoconus patients along with significant decreases in IL-12. IL-17 has been implicated in corneal inflammation and stimulates stromal cells to produce other proinflammatory cytokines. ${ }^{102}$ They could not detect by multiplex immuno-bead assay the levels IL-17 in tears of keratoconus patients, but they found an increase by conventional ELISA on a limited number of pooled tear samples. In addition, they found lower levels of TNF- $\alpha$, an observation that disagrees with reports from Lema et al ${ }^{20,21,22}$ and Balasubramanian et al. ${ }^{18}$ The possible reasons for this disparity could be either artefactual differences in the antibody-based assays or real differences between patient populations. ${ }^{103}$

Whether the altered protein composition of tears in eyes suffering from keratoconus is an effect of events in the corneal epithelium or has a direct influence in the development of the disease remains to be elucidated. ${ }^{96}$

Cheung et al ${ }^{86}$ recently analyzed ex vivo the modulation of the healing process of corneas with keratoconus and of non-keratoconic corneas. The affected corneas had higher levels of IL-1 $\alpha$, IGF-1 (insulin-like growth factor 1), TNF- $\alpha$, and TGF-B1 (TGF $\beta$ - 1 ) than normal corneas, and lower levels of HGF and B-NGF ( $\beta$-nerve growth factor). It is known that IL- $1 \alpha$ and TNF- $\alpha$ triggers apoptosis of keratocytes, and additionally those cytokines may enhance collagen turnover.

Neutrophil-to-lymphocyte ratio (NLR), which is the total count of neutrophils divided by those of lymphocytes, is a new potential predictor of systemic inflammation in several diseases. Karaca et al ${ }^{104}$ have just reported the results of a cross-sectional observational study, which included 54 patients with keratoconus and 25 age- and sex-matched control subjects. They found that there was a positive correlation between NLR and progression of the disease, and consequently concluded that their results supported the relationship between the progression of keratoconus and increased systemic inflammatory response. ${ }^{104}$

Kolozsvári et al ${ }^{105}$ evaluated the effect of the corneal cross-linking procedure on different tear biomarkers.
They included 23 eyes with keratoconus and 12 normal eyes used as controls. Six months after the procedure, they found a significant increase in t-PA in tear samples, wherein the level was higher at baseline in keratoconic eyes than in controls. t-PA is an enzyme that catalyzes the conversion of plasminogen to plasmin, which in turn causes fibrinolysis dissolving fibrin blood clots. However, in addition, plasmin activates collagenases and it is related to fibroblast collagen synthesis inhibition by the action of PGE2 (Bauman et $a{ }^{91}$ ). At 12 months, they observed a significant decrease in IL-6 and CXCL8 (IL-8). The levels of these two cytokines on healthy eyes used as controls in that study were also significantly lower compared with the baseline levels of keratoconic corneas; thus, the decrease of those levels might be a contributing factor in the stabilization of the disease. Their baseline findings that keratoconus index measured by Pentacam correlated negatively with Chemokine ( $\mathrm{C}-\mathrm{C}$ motif) ligand 5 (CCL5) was in line with Jun et al's report. ${ }^{103}$ Their baseline observation and the reversely significant association found by them between the thinnest corneal thickness as measured by Pentacam and CCL5, 1 year after corneal cross-linking, might indicate a role of CCL5 in the etiopathology of the condition. ${ }^{105}$

Several researchers have concluded that inadequate balance between cytokines (pro-inflammatory and antiinflammatory) may lead to an altered corneal structure and function, triggering an increase in metalloproteinases and keratocyte apoptosis. ${ }^{74,103,106}$

Kolozsvári et al ${ }^{107}$ also recently found a significant positive association between CCL5, MMP-13, and NGF and several topographic indices in keratoconic corneas. In addition, they found a significant negative correlation between IL-6 and Klyce/Maeda keratoconus index. Agedependent associations were observed between IL-13, CXCL8 (IL-8), CCL5, and MMP-13 and the topographic data. Their findings suggest that some mediators might have different effects on the severity of disease in an agedependent manner. ${ }^{107}$

Low levels of lactoferrin, IgA, ZAG (zinc- $\alpha 2$ glycoprotein), and IGKC (immunoglobulin $\kappa$-chain) have also been found in tears of patients with keratoconus. ${ }^{19,108}$ Lactoferrin and IgA seem to have the greatest impact on the disease because of their immunomodulatory and antiinflammatory properties (lactoferrin inhibits IL-1, IL-2, IL- 6 , and TNF- $\alpha$; IgA inhibits the immune response through Fc $\alpha$ RI receptor). ${ }^{109,110}$

In 1961, Ridley ${ }^{115}$ related eye rubbing with keratoconus, and many researchers have later confirmed that finding. ${ }^{72,111-118}$ Bawazeer $e t a l^{11}$ published the results of a case-control study, which showed, using multivariate analysis, that eye rubbing was a significant predictor of keratoconus. The mechanical factor may have a role, causing an increase in both corneal temperature 
(secondary to friction with the conjunctiva) and intraocular pressure as McMonnies et al ${ }^{112,119}$ has pointed out. In addition, effects of the rubbing at molecular level have been identified as well. In 2013, Balasubramanian et $a l^{120}$ found that eye rubbing increased the level of tear MMP-13, IL-6, and TNF- $\alpha$ in normal eyes and in keratoconus. Accordingly, persistent eye rubbing might cause an even greater and sustained increase in the levels and activity of these cytokines, and thus those inflammatory molecules may be causal links between eye rubbing and keratoconus.

As Mcmonnies ${ }^{25}$ recently highlighted, another argument supporting the role of proinflammatory chemokines in corneal thinning is that in ocular rosacea several cases of pseudo-keratoconus have been reported. ${ }^{121,122}$ Afonso et al ${ }^{123}$ found higher concentration of IL- $1 \alpha$ and greater activity of MMP-9 in the tear fluid of patients with ocular rosacea than in control subjects.

Table 1 summarizes the most relevant studies on this topic.

An important limitation of all these studies, relating a disbalance in cytokines (pro-inflammatory and antiinflammatory), is that they cannot exclude the possibility of other mediators being involved in the etiopathogenesis of keratoconus, and that the identification of the source and activity of the mediators and the expression of the different receptors are topics still to be solved.

\section{Enzymatic imbalance}

MMPs, a group of zinc-dependent endopeptidases that include gelatinases (MMP-2 and -9), collagenases (MMP-1, -8, and -13), stromelysins (MMP-3 and -10), and matrilysins (MMP-7 and -26) synthesized by corneal epithelial cells and stromal cells, have long been suspected of having a significant role in keratoconus. Kao et al, ${ }^{124}$ as early as 1982 , determined that the amount of collagen decreased and solubility of collagen increased in keratoconic corneas, and that they possessed substantially more collagenase and gelatinase activities than normal corneas. Nelidova and Sherwin ${ }^{75}$ in a book chapter and Balasubramanian et al ${ }^{125}$ in an article have published very complete reviews on the topic. Degradation of corneal stroma in keratoconus involves the expression of inflammatory mediators, including proinflammatory cytokines and cell adhesion molecules, which modulate MMP activity and are themselves modulated by it. MMPs, cytokines, and cathepsin S (CATS) have been found to exhibit complex interactions with each other. IL-1b, IL-6, or TNF- $\alpha$ (A) can stimulate the production of several MMPs (-1, -2, $-3,-7,-9$, and -13) and CATS. Levels of MMP-1, $-2,-3$, and -9 can inactivate IL- $1 \beta$ and IL-10 has an inhibitory effect on CATS. ${ }^{18}$ All of these findings support the role of chronic inflammatory events in the pathogenesis of keratoconus. ${ }^{22,106}$

Another factor could be enhanced MMP-2 activity through overproduction of this protein, whose proenzyme (proMMP-2) is overexpressed in keratoconic corneas. ${ }^{126-128}$

Production of MMPs is regulated by IL; IL-1, IL-6, IL-7, and TNF- $\alpha$ increase MMP-1, MMP-3, MMP-9, and MMP-13, whereas IL-10 diminishes cathepsins. The enzymatic activity is a result of the balance with its inhibitors (tissue inhibitor of MMP (TIMP)); therefore, its function may increase not only because of a higher IL level but also because of lower level of inhibitors. ${ }^{129-131}$

One study found higher concentrations of C-terminal telopeptide (type I collagen degradation products) in tears of patients with keratoconus than in controls. ${ }^{132}$ This behavior is due to the increase of activity and number of enzymes that remodel the ECM; the most prominent changes in keratoconic cornea were observed in collagenase MMP-13, and in particular, in cathepsin $\mathrm{K}$ and human trypsin-2, which were strongly expressed in keratoconus, suggesting a role in intra- and extracellular pathological collagen destruction, respectively. ${ }^{23} \mathrm{~A}$ similar report documented 1.9 times more proteolytic activity and gelatinases/collagenases expression (MMP-1, MMP-3, MMP-7, and MMP-13, as well as IL-4, IL-6, and TNF- $\alpha$ that increase the production and activity of the former). ${ }^{18}$ Table 1 lists studies on MMP levels in keratoconus.

A study in pregnant women reported a progression of keratoconus during the pregnancy and a post-partum stabilization. Proposed theories for this event are negative regulation of estrogens on the cornea's biomechanical properties and direct influence of relaxin on the increment of MMP synthesis and decrement of its inhibitors. ${ }^{133-135}$

Recently, LOX has been the target of numerous studies given its potential for applications in ophthalmology. LOX is an amine oxidase that confers mechanical properties to the connective tissue. It oxidates peptidyl lysine and hydroxylysine residues present in collagen and lysine present in elastin, to produce peptidyl $\alpha$-aminoadipic- $\delta$-semialdehydes. These can spontaneously combine with neighbor aldehydes or epsilon amino groups of peptidyl lysine, to create covalent unions that stabilize collagen and elastin fibers of the EMC and make them insoluble. ${ }^{136}$

Polymorphisms of the LOX coding gene are correlated with an increased likelihood to develop keratoconus. ${ }^{137,138}$ In 63\% of cases of keratoconus, LOX distribution has been found to be markedly decreased and its activity to be more than 2.5 times lower than that of control cases. ${ }^{139,140}$ A study in Russia has shown that the increase in $\mathrm{pH}$ of the tears causes biochemical changes in the periphery of the cornea that prevent the passage of 


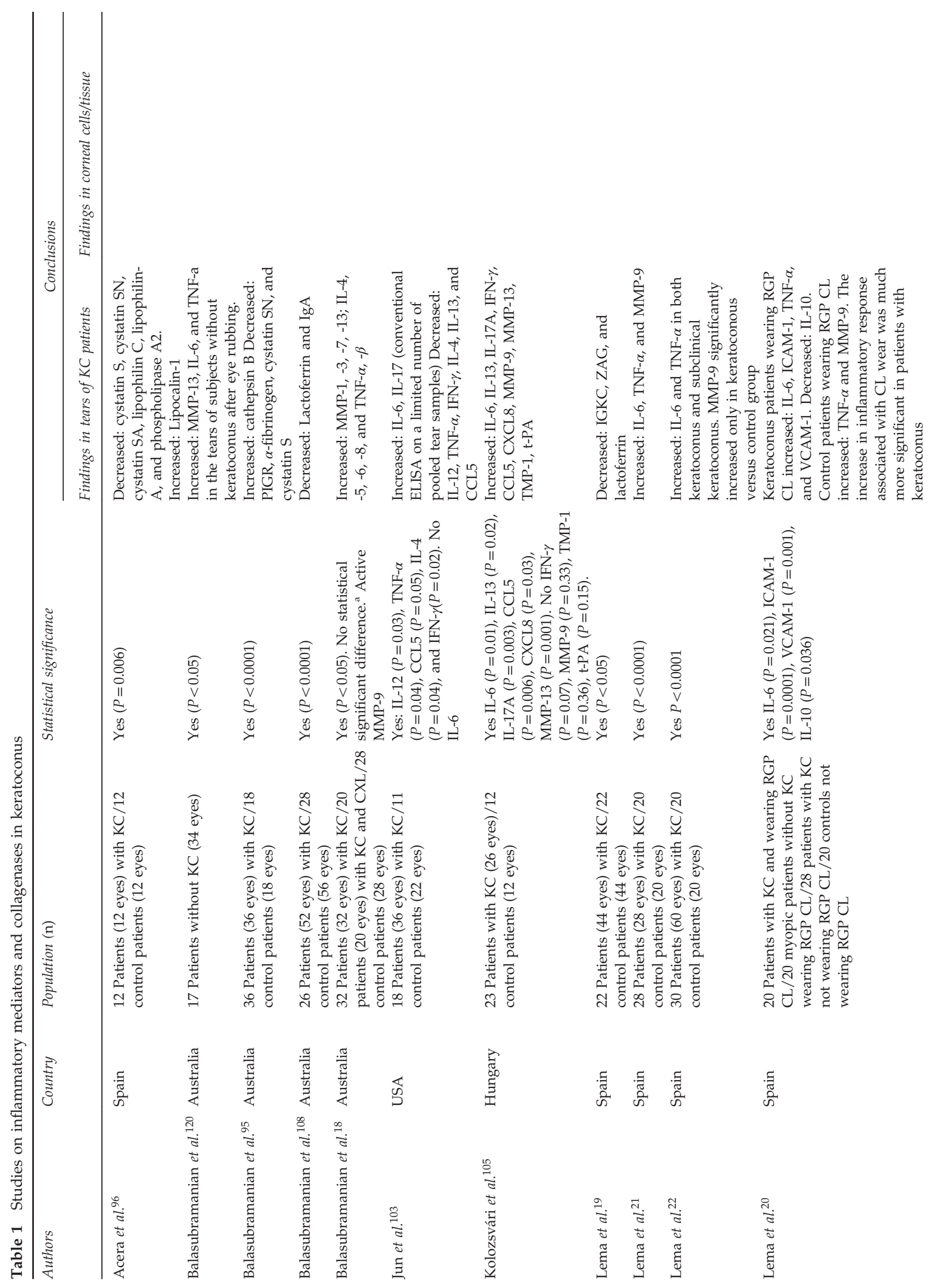




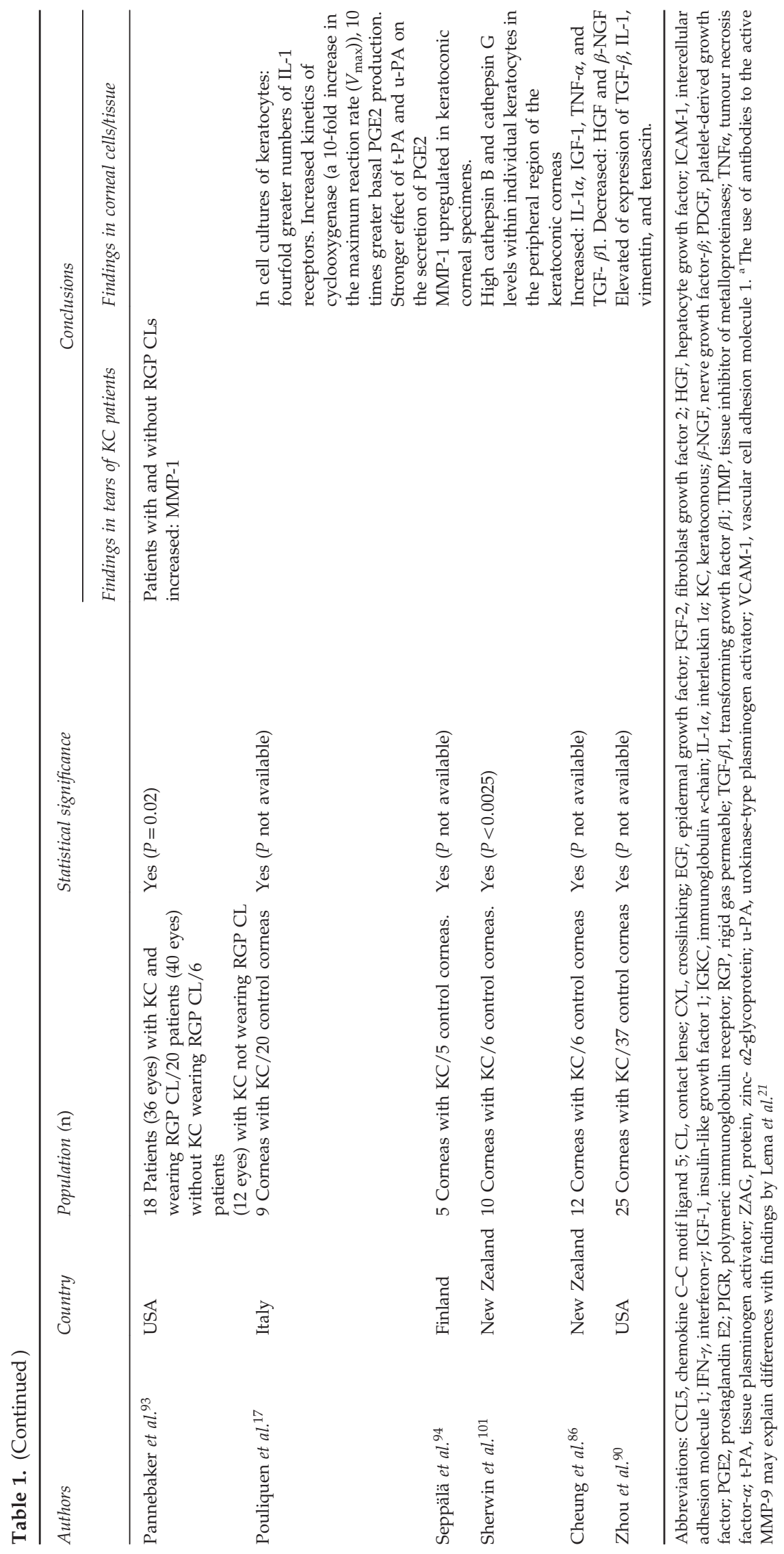


copper to its center. Dichlorocuprate ion low concentrations inactivate LOX and could be a promoting factor of keratoconus progression. ${ }^{141}$

\section{Oxidative stress}

One of the most important functions of the cornea, although usually forgotten, is to neutralize free radicals and oxidants (ROS/RNS) that are typically formed from cellular metabolism and from exposure to the ultraviolet light of the sun. To perform this function, it has powerful enzymes such as enzyme SOD, glutathione peroxidase, nicotinamide adenine dinucleotide phosphate, and catalase, and antioxidant molecules of low molecular weight (a-tocopherol, ascorbate, ferritin, and proteoglycans). ${ }^{142}$

When a shortage of these molecules is present, the levels of ROS and RNS remain high and damage the DNA and the mitochondrial respiratory chain, denaturize proteins, and cause lipid peroxidation, which further generates free radicals, thereby entering in a vicious cycle of oxidation. ${ }^{73}$

Keratocytes are particularly susceptible to oxidative stress and it may have an important role in the development and progression of keratoconus. Keratoconus corneas have been shown to have a decreased glutathione content and total antioxidant capacity, ${ }^{143}$ which can be related to increased oxidative stress that may induce oxidative damage to tissue components. ${ }^{106,144}$ Thus, alterations of these antioxidant pathways may lead to accumulation of toxic byproducts, which eventually may induce apoptosis of the corneal cells.

Whether the changes observed in keratoconic corneas related to oxidative damage are linked to the effect of systemic oxidative stress is an issue still under investigation. Jun et al ${ }^{103}$ found that in the sera of keratoconus patients, there were no statistically significant differences between them and control subjects for several cytokines tested, and suggested that the cytokine changes detected in the tear film were most likely a consequence of localized events in the eye and not of systemic changes.

However, more recently Toprak et al ${ }^{145}$ found that serum total oxidant status and oxidative stress index values were significantly higher in patients with keratoconus compared with those of the controls, suggesting that systemic oxidative stress might be involved in the pathogenesis of the condition. The recent findings by Karaca et al ${ }^{104}$ with regard to NLR, already mentioned, also seem to support a relationship between the progression of keratoconus and increased systemic inflammatory response.
Patients with keratoconus recorded higher concentrations of ROS, RNS, and cytotoxic aldehydes (product of lipid peroxidation), as well as a significant decrease in the total antioxidant capacity of the cornea. ${ }^{63,143,144,146}$ In addition, in vitro studies have shown that IL- $1 \alpha$, which is high in keratoconus, has the ability to decrease the synthesis of the SOD, whereby antioxidant defenses become insufficient. ${ }^{147} \mathrm{NO}$ is an endogenous substance, which regulates complex processes in ocular tissues. ${ }^{148}$ TIMP attenuation by peroxynitrates has been well studied. In vitro studies have reported a reduction to zero in the activity of TIMP (TIMP-1), with a simultaneous increase in the activity of MMPs (MMP-2). ${ }^{149}$

Accordingly with the findings of an increased oxidative stress in keratoconic corneas, and as Kenney et $a l^{73}$ suggested in 2003, the evidence supports that the practitioners recommend ultraviolet light protection for keratoconus patients. ${ }^{76}$

Recently, riboflavin has been evaluated experimentally in vitro as a therapeutic option because of its antioxidant effect, in cultured human stromal cells from keratoconic corneas by Cheung et al. ${ }^{150}$ The results are encouraging: it was possible to increase normal formation of the ECM and significantly lower levels of ROS. ${ }^{150}$

\section{Cellular hypersensitivity}

Studies performed around 20 years ago by Pouliquen et $a l^{17}$, Fabre et $a l^{16}$, Bureau et $a l^{15}$ in France demonstrated that keratocytes from eyes with keratoconus have fourfold greater numbers of IL-1 receptors, a proinflammatory cytokine, than keratocytes from normal eyes. Wilson et al ${ }^{152}$ hypothesized that keratoconic keratocytes had increased sensitivity to IL-1 released from the corneal epithelial cells, leading to gradual loss of stromal mass in susceptible corneas by means of cellular death (apoptosis). ${ }^{151}$ Unlike a normal cornea without injury, where keratocyte apoptosis is negligible, this process of programmed cell death is much more common in a cornea with keratoconus. ${ }^{106}$ IL-1 has also additional effects on the corneal stroma: upregulation of collagenase, metalloproteinase, HGF, keratyinocyte growth factor expression, and production of IL-6 in keratocytes. ${ }^{89,153-155}$ The IL-1 family comprises two proinflammatory cytokines (IL- $1 \alpha$ and IL- $1 \beta$ ) and the IL- 1 receptor antagonist (IL-1 Ra). Although IL- $1 \alpha$ and IL- $1 \beta$ are expressed from separate genes, both of them mediate their effects binding the same IL-1 receptor type 1 (IL-1 R). ${ }^{87,88}$ IL-1Ra regulates IL- $1 \alpha$ and IL- $1 \beta$ proinflammatory activity by competing with them for binding sites of the receptor IL-1R.

Kim et al ${ }^{60}$ published a genetic study in Korean patients, which suggested that two single-nucleotide 
polymorphisms in IL- $1 \beta$ gene were related to keratoconus predisposition, and recently Mikami et al ${ }^{61}$ published a similar relation in Japanese patients. However, a recent study in a Turkish population by Palamar et al ${ }^{62}$ found no clear relation between the IL-1 $\beta$ gene polymorphism and the receptor antagonist IL-1 (ILRN VNTR) with the possibility of keratoconus development.

In vitro studies have shown that in oxidative stress environments with low $\mathrm{pH}$, fibroblasts tend to increase the activation of the caspases (caspase-9 and -12), suffer mitochondrial dysfunction, and undergo DNA damage more often than controls. ${ }^{156} \mathrm{~A}$ factor influencing the increased gelatinase activity and apoptosis of keratoconus could be the decreased TIMP-1 activity. It has been proposed that TIMP-1 restrains the activity of MMP-2, the major protease of the corneal stroma. ${ }^{157-159}$ Matthews et $a^{159}$ showed that overexpression of TIMP-3 induced apoptosis in corneal stromal cell cultures, and that upregulated TIMP-1 production or the addition of exogenous TIMP-1 protein prevented stromal cell overgrowth, changed stromal cell morphology, and reduced the extent of TIMP-3-induced apoptosis. These unique characteristics are important in cases of keratoconus considering the imbalances in the levels of these modulators and the increased sensitivity of cells to them.

One study on protein expression of cytokines related to stromal wound healing and the effect of an induced secondary injury on stromal cells from ex vivo human keratoconus and control corneas found that wounded keratoconic corneas may be less capable of showing a normal reparative response. ${ }^{74}$

A significant reduction of the $\beta$-actin gene expression in the corneal stroma and, using immunofluorescence detection, a complete loss of this protein in the corneal fibroblast in keratoconus, have been found. It has been suggested that the absence of $\beta$-actin may induce destabilization of the cytoskeleton of keratocytes and apoptosis. ${ }^{160}$

\section{Conclusion}

Developing an understanding of the pathophysiological mechanisms of keratoconus will certainly allow the formulation and implementation of new, more effective, and safe therapeutic procedures, to provide novel treatments for our patients.

Scientific evidence has shown that keratoconus is a multifactorial disease involving complex interaction of both genetic and environmental factors, which allows a 'two-hit hypothesis', that is, a genetic predisposition to the corneal disease and a second hit that may induce abnormalities of any of the inflammatory components discussed (Figure 1). Eye rubbing is a proven factor that triggers the onset and progression of the disease, through several effects including stimulation of inflammation. ${ }^{112,113,119,120}$ Increasing evidence supports the fact that thinning and ectasia of the cornea are related to a degraded extracellular matrix involving inflammatory events (mainly increased levels of MMP-9, IL-6, and TNF- $\alpha)^{10,12-14,67,91}$ and increased oxidative stress. ${ }^{143-146}$ However, the precise role of each of the identified molecular factors still needs to be defined in further studies.

As its official description by Nottingham, more than 150 years ago, until today, keratoconus has been defined as a non-inflammatory disease based on the absence of neovascularization and lack of marked cellular infiltration; nevertheless, the definition of inflammation should not necessarily be limited to these two conditions. In addition, Kenney et al, ${ }^{161}$ using immunohistochemistry, found that keratoconus corneas showed increased numbers of glycoprotein cluster of differentiation 68 (CD68)-positive cells within the stroma, and that the epithelial basement membrane in keratoconus corneas stained with that antibody. As CD68 is expressed on macrophages and their precursors, monocytes, and is also present to a lesser extent on dendritic cells and peripheral blood granulocytes, those findings could be a suggestion of at least some degree of cellular infiltration with inflammatory cells in the keratoconic cornea, which would support the role of inflammation in keratoconus pathophysiology. ${ }^{161}$ However, in contrast with that investigation, two studies did not find positive results for antibody markers for CD68 in keratoconus. ${ }^{162,163}$ Sykakis et al $^{164}$ reported in 2012 that they identified both isolated and aggregated nuclei at sites of Bowman's breaks in keratoconic corneas, for which the origin could not be identified (they did not look for the immunohistochemical expression of anti-CD68 antibody).

Following the suggestion of Lema et $a l^{21}$ and the opinion of several other researchers (McMonnies ${ }^{112}$, Solomon ${ }^{165}$, Kolozsvári, ${ }^{105}$ and Fodor ${ }^{105}$ ), we also consider the concept that keeping the already demonstrated involvement of inflammatory mediators in the pathophysiology of keratoconus classified as a noninflammatory condition may be no longer adequate. ${ }^{21,74,100,112,165}$ Keratoconus could be an inflammatory disorder.

As McMonnies ${ }^{25}$ recently pointed out, there is another disease (osteoarthritis), which also has certain features of inflammation but does not meet all the classic criteria for the definition of inflammation. Under physical stress, changes in gene expression and an increase in production of inflammatory cytokines and matrix-degrading enzymes have been noted in the cartilaginous tissue. ${ }^{166}$ All these biochemical findings have generated a controversy about the inflammatory nature of the 


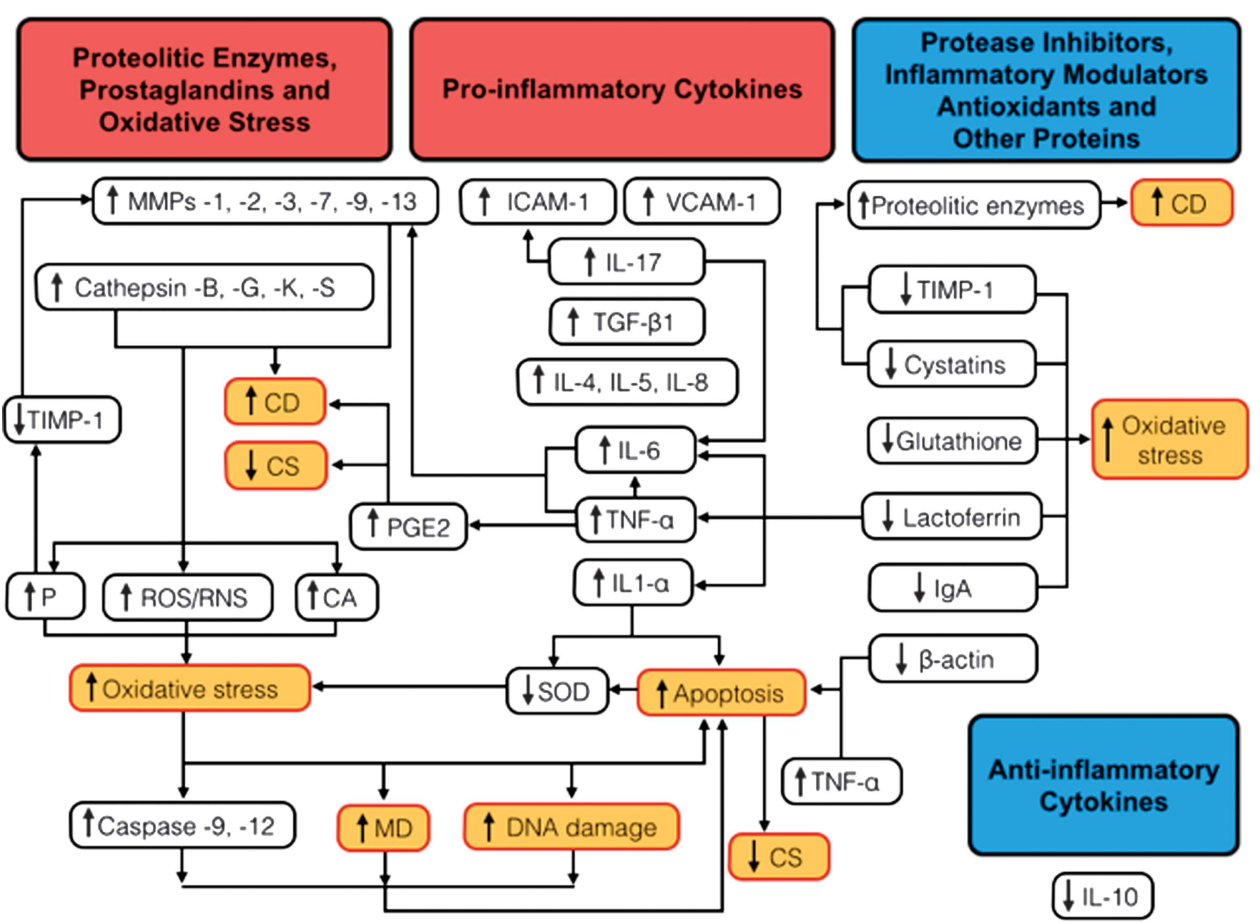

Figure 1 The inadequate balance between pro-inflammatory cytokines, proteolitic enzymes, protease inhibitors, inflammatory modulators, and antioxidants may lead to an altered corneal structure and function in keratoconus, triggering a vicious circle between oxidative stress, keratocyte apoptosis, and increased activity of metalloproteinases. ${ }^{74,103,105}$ On cell cultures of keratocytes from keratoconic corneas, basal PGE2 production was found to be 10 times greater than in normals. ${ }^{17}$ PGE2, whose release may be induced by TNF- $\alpha$, has been shown to have inhibitory effects on collagen synthesis (CS) and to increase collagen degradation (CD). The tear film in keratoconus have shown increased levels of pro-inflammatory molecules: IL- $1 \alpha,-4,-5,-6,-8$, and -17, TNF- $\alpha$, TGF-B1 (TGF $\beta-1)$, ICAM-1, and VCAM-1. ${ }^{18,20,21,86,103} \beta$-Actin gene has been found to be downregulated and the protein absent in corneal buttons from keratoconus patients. ${ }^{160}$ The elevated levels of IL-1- $\alpha$ and TNF- $\alpha$, and low levels of $\beta$-actin have been related to triggering apoptosis of keratocytes. ${ }^{86,151,152,160}$ In keratoconus, levels of proteases such as lysosomal cathepsin-B, $-\mathrm{G},-\mathrm{K}$, and $-\mathrm{S}$, and metalloproteinases (MMPs) are elevated. IL- 6 and TNF- $\alpha$ can stimulate the production of several MMPs $(-1,-2,-3,-7,-9$, and -13$)$ and CATS. 18,21,23,75,93,125 There is also a decrease in the levels of several antioxidant or anti-inflammatory molecules: SOD, glutathione, lactoferrin, IgA, and IL-10. 19,20,106,108-110,144 An important decrease in the level of protease inhibitors such as cystatins (inhibitors of cysteine proteases) and TIMP-1 (inhibitor of MMPs) have also been reported. ${ }^{95,96,101,129-131}$ The increased activity of several proteolytic enzymes results in higher concentrations of ROS, RNS, cytotoxic aldehydes (CAs) and peroxynitrates (Ps) (which decreases the activity of TIMP-1 and increase MMP-2), ${ }^{63,143,144,146,149}$ and given the lower production of SOD ${ }^{143}$ possibly related to IL- $1 \alpha^{158}$ an environment with high oxidative stress and low $\mathrm{pH}$ is formed, causing an increase in the activation of the caspases (caspase-9 and -12), mitochondrial dysfunction (MD), and DNA damage, ${ }^{156}$ which eventually lead to increased apoptosis. All of these could probably be the result of a complex interaction of both genetic predisposition and environmental triggering factors, such as eye rubbing and contact lenses wear (the 'two-hit hypothesis') in keratoconus. ${ }^{42,52,100,113,119,120}$

condition (similar to the case with keratoconous). It has been proposed that although the disorder does not meet the definition of inflammatory, based on the numbers of leukocytes in synovial fluid, the presence of proinflammatory mediators, which perpetuate disease progression, warrants a reconsideration of the definition of inflammation. . $^{167-169}$

However, with regard to keratoconus, several issues are still to be solved: Why is it that many laboratory studies are indicating elevated levels of inflammatory markers in keratoconus, but clinical and histological findings show little evidence of this inflammation, that is, no significant cell infiltration or neovascularization?
Is the mere presence of those markers in keratoconic corneas a sufficient proof of inflammation or does it need to be quantitatively compared with the levels of the same markers in corneal diseases with clinically evident inflammation? It is possible that these findings correspond to epiphenomena, a possibility already suggested by Lema et al. ${ }^{22}$

As suggested by McMonnies, ${ }^{25}$ should a new category of diseases be established: quasi-inflammatory or inflammatory- related conditions?

Undoubtedly, future studies with a larger number of healthy eyes used as controls, and comparison of the levels of these markers in eyes with other inflammatory 
conditions in the cornea, will contribute to elucidate these questions and ultimately help to unravel the etiological mysteries of keratoconus. The tear film proteome has become and will stay as an area of high interest for the identification of potential targets for early diagnosis and therapy in these patients, due to its non-invasive nature. ${ }^{170}$

\section{Conflict of interest}

The authors declare no conflict of interest.

\section{References}

1 Rabinowitz YS. Keratoconus. Surv Ophthalmol 1998; 42 297-319.

2 Krachmer JH, Feder RS, Belin MW. Keratoconus and related noninflammatory corneal thinning disorders. Surv Ophthalmol 1984; 28: 293-322.

3 Davidson AE, Hayes S, Hardcastle AJ, Tuft SJ. The pathogenesis of keratoconus. Eye (Lond) 2014; 28: 189-195.

4 Brunsting LA, Reed WB, Bair HL. Occurrence of cataracts and keratoconus with atopic dermatitis. AMA Arch Derm 1955; 72: 237-241.

5 Spencer WH, Fisher JJ. The association of keratoconus with atopic dermatitis. Am J Ophthalmol 1959; 47: 332-344.

6 Harrison RJ, Klouda PT, Easty DL, Manku M, Charles J, Stewart CM. Association between keratoconus and atopy. Br J Ophthalmol 1989; 73: 816-822.

7 Kok YO, Tan GF, Loon SC. Review: keratoconus in Asia. Cornea 2012; 31: 581-593.

8 Millodot M, Shneor E, Albou S, Atlani E, Gordon-Shaag A. Prevalence and associated factors of keratoconus in Jerusalem: a cross-sectional study. Ophthalmic Epidemiol 2011; 18: 91-97.

9 Kemp EG, Lewis CJ. Measurement of total and specific IgE levels in the management of a family exhibiting a high incidence of keratoconus. Acta Ophthalmol (Copenh) 1984; 62: 524-529.

10 Kemp EG, Lewis CJ. Immunoglobulin patterns in keratoconus with particular reference to total and specific IgE levels. Br J Ophthalmol 1982; 66: 717-720.

11 Bawazeer AM, Hodge WG, Lorimer B. Atopy and keratoconus: a multivariate analysis. Br J Ophthalmol 2000; 84: 834-836.

12 Fukuchi T, Yue B, Sugar J, Lam S. Lysosomal enzyme activities in conjunctival tissues of patients with keratoconus. Arch Ophthalmol 1994; 112: 1368-1374.

13 Sawaguchi S, Yue BY, Sugar J, Gilboy JE. Lysosomal enzyme abnormalities in keratoconus. Arch Ophthalmol 1989; 107: 1507-1510.

14 Zhou L, Sawaguchi S, Twining SS, Sugar J, Feder RS, Yue BY. Expression of degradative enzymes and protease inhibitors in corneas with keratoconus. Invest Ophthalmol Vis Sci 1998; 39: 1117-1124.

15 Bureau J, Fabre EJ, Hecquet C, Pouliquen Y, Lorans G. Modification of prostiglandin E2 and collagen synthesis in keratoconus fibroblasts associated with an increase of interleukin 1 alpha receptor number. C R Acad Sci III 1993; 316: 425-430.

16 Fabre EJ, Bureau J, Pouliquen Y, Lorans G. Binding sites for human interleukin 1 alpha, gamma interferon and tumor necrosis factor on cultured fibroblasts of normal cornea and keratoconus. Curr Eye Res 1991; 10: 585-592.

17 Pouliquen Y, Bureau J, Mirshahi M, Mirshahi SS, Assouline M, Lorens G. Keratoconus and inflammatory processes. Bull Soc Belge Ophtalmol 1996; 262: 25-28.

18 Balasubramanian SA, Mohan S, Pye DC, Willcox MD. Proteases, proteolysis and inflammatory molecules in the tears of people with keratoconus. Acta Ophthalmol 2012; 90: e303-e309.

19 Lema I, Brea D, Rodríguez-González R, Díez-Feijoo E, Sobrino T. Proteomic analysis of the tear film in patients with keratoconus. Mol Vis 2010; 16: 2055-2061.

20 Lema I, Durán JA, Ruiz C, Díez-Feijoo E, Acera A, Merayo J. Inflammatory response to contact lenses in patients with keratoconus compared with myopic subjects. Cornea 2008; 27: 758-763.

21 Lema I, Durán JA. Inflammatory molecules in the tears of patients with keratoconus. Ophthalmology 2005; 112: 654-659.

22 Lema I, Sobrino T, Durán JA, Brea D, Díez-Feijoo E. Subclinical keratoconus and inflammatory molecules from tears. Br J Ophthalmol 2009; 93: 820-824.

23 Mackiewicz Z, Määttä M, Stenman M, Konttinen L, Tervo T, Konttinen YT. Collagenolytic proteinases in keratoconus. Cornea 2006; 25: 603-610.

24 Sugar J, Macsai MS. What causes keratoconus? Cornea 2012; 31: 716-719.

25 McMonnies CW. Inflammation and keratoconus. Optom Vis Sci 2014 Epub ahead of print.

26 Tachibana M, Okamoto M, Sakamoto M, Matsushima Y. Hereditary keratoconus-like keratopathy in Japanese wild mice mapped to mouse Chromosome 13. Mamm Genome 2002; 13: 692-695.

27 Tachibana M, Adachi W, Kinoshita S, Kobayashi Y, Honma $\mathrm{Y}$, Hiai $\mathrm{H}$ et al. Androgen-dependent hereditary mouse keratoconus: linkage to an MHC region. Invest Ophthalmol Vis Sci 2002; 43: 51-57.

28 Héon E, Greenberg A, Kopp KK, Rootman D, Vincent AL, Billingsley G et al. VSX1: a gene for posterior polymorphous dystrophy and keratoconus. Hum Mol Genet 2002; 11: 1029-1036.

29 Gorskova EN, Sevostianov EN. [Epidemiology of keratoconus in the Urals]. Vestn Oftalmol 1998; 114: 38-40.

30 Jonas JB, Nangia V, Matin A, Kulkarni M, Bhojwani K. Prevalence and associations of keratoconus in rural Maharashtra in central India: the central India Eye Medical Study. Am J Ophthalmol 2009; 148: 760-765.

31 Hashemi H, Khabazkhoob M, Yazdani N, Ostadimoghaddam H, Norouzirad R, Amanzadeh $\mathrm{K}$ et al. The prevalence of keratoconus in a young population in Mashhad, Iran. Ophthalmic Physiol Opt 2014; 34: 519-527.

32 Kennedy R, Bourne W, Dyer J. A 48-year clinical and epidemiologic study of keratoconus. Am J Ophthalmol 1986; 101: 267-273.

33 Bamashmus M, Saleh MF, Abdulrahman M, Al-Kershy N. Reasons for not performing LASIK in refractive surgery candidates in Yemen. Eur J Ophthalmol 2010; 20: 858-864.

34 Nilforoushan MR, Speaker M, Marmor M, Abramson J, Tullo W, Morschauser D et al. Comparative evaluation of refractive surgery candidates with Placido topography, Orbscan II, Pentacam, an wavefront analysis. J Cataract Refract Surg 2008; 34: 623-631. 
35 Sharma N, Singhvi A, Sinha R, Vajpayee RB. Reasons for not performing LASIK in refractive surgery candidates. J Refract Surg 2005; 21: 496-498.

36 Varssano D, Kaiserman I, Hazarbassanov R. Topographic patterns in refractive surgery candidates. Cornea 2004; 23: 602-607.

37 Galvis V, Tello A, Jaramillo JA, Gutierrez AJ, Rodriguez L, Quintero MP. Prevalence of keratoconus patients who consulted with a desire refractive surgery in ophthalmology center reference Bucaramanga, Colombia. Rev Soc Colomb Oftal 2011; 44: 129-134.

38 Li X, Rabinowitz YS, Rasheed K, Yang H. Longitudinal study of the normal eyes in unilateral keratoconus patientes. Ophthalmology 2004; 111: 440-446.

39 Georgiou T, Funnell CL, Cassels-Brown A, O'Conor R. Influence of ethnic origin on the incidence of keratoconus and associated atopic disease in Asians and white patients. Eye (lond) 2004; 18: 379-383.

40 Pearson AR, Soneji B, Sarvananthan N, Sandford-Smith JH Does ethnic influence the incidence or severity of keratoconus? Eye (Lond) 2000; 14: 625-628.

41 Gokhale NS. Epidemiology of keratoconus. Indian J Ophthalmol 2013; 61: 382-383.

42 Edwards M, McGhee CN, Dean S. The genetics of keratoconus. Clin Experiment Ophthalmol 2001; 29: 345-351.

43 Woodward EG, Morris MT. Joint hypermobility in keratoconus. Ophthalmic Physiol Opt 1990; 10: 360-362.

44 Kalkan Akcay E, Akcay M, Uysal BS, Kosekahya P, Aslan AN, Caglayan M et al. Impaired corneal biomechanical properties and the prevalence of keratoconus in mitral valve prolapse. J Ophthalmol 2014; 2014: 402193.

45 Nielsen K, Hjortdal J, Pihlmann M, Corydon TJ. Update on the keratoconus genetics. Acta Ophthalmol 2013; 91: 106-113.

46 Tuft SJ, Hassan H, George S, Frazer DG, Willoughby CE, Liskova P. Keratoconus in 18 pairs of twins. Acta Ophthalmol 2012; 90: e482-e486.

47 Rabinowitz YS. The genetics of keratoconus. Ophthalmol Clin North Am 2003; 16: 607-620.

48 Burdon KP, Coster DJ, Charlesworth JC, Mills RA, Laurie KJ, Giunta C et al. Apparent autosomal dominant keratoconus in a large Australian pedigree accounted for by digenic inheritance of two novel loci. Hum Genet 2008; 124 379-836.

49 Gordon-Shaag A, Millodot M, Essa M, Garth J, Ghara M, Shneor E. Is consanguinity a risk factor for keratoconus? Optom Vis Sci 2013; 90: 448-454.

50 Kriszt A, Losonczy G, Berta A, Vereb G, Takács L. Segregation analysis suggests that keratoconus is a complex non-mendelian disease. Acta Ophthalmol 2014; 92: e562-e568.

51 Novak DM, Gajecka M. The genetics of keratoconus. Middle East Afr J Ophthalmol 2011; 18: 2-6.

52 Abu-Amero KK, Al-Muammar AM, Kondkar AA. Genetics of keratoconus: where do we stand? J Ophthalmol 2014; 2014: 641708.

53 Czugala M, Karolak JA, Nowak DM, Polakowski P, Pitarque J, Molinari A et al. Novel mutation and three other sequence variants segregating with phenotype at keratoconus 13q32 susceptibility locus. Eur J Hum Genet 2012; 20: 389-397.

54 Gajecka M, Radhakrishna U, Winters D, Nath SK Rydzanicz M, Ratnamala U et al. Localization of a gene for keratoconus to a $5.6-\mathrm{Mb}$ interval on $13 \mathrm{q} 32$. Invest Ophthalmol Vis Sci 2009; 50: 1531-1539.
55 Wheeler J, Hauser MA, Afshari NA, Allingham RR, Liu Y. The genetics of keratoconus: a review. Reprod Syst Sex Disord 2012; (Suppl 6). pii: 001.

56 Lechner J, Bae HA, Guduric-Fuchs J, Rice A, Govindarajan G, Siddiqui $S$ et al. Mutational analysis of MIR184 in sporadic keratoconus and myopia. Invest Ophthalmol Vis Sci 2013; 54: 5266-5272.

57 Li X, Rabinowitz YS, Tang YG, Picornell Y, Taylor KD, $\mathrm{Hu} \mathrm{M}$ et al. Two-stage genome-wide linkage scan in keratoconus sib pair families. Invest Ophthalmol Vis Sci 2006; 47: 3791-3795.

58 Burdon KP, Macgregor S, Bykhovskaya Y, Javadiyan S, Li X, Laurie KJ et al. Association of polymorphisms in the hepatocyte growth factor gene promoter with keratoconus. Invest Ophthalmol Vis Sci 2011; 52: 8514-8519.

59 Sahebjada S, Schache M, Richardson AJ, Snibson G, Daniell M, Baird PN. Association of the hepatocyte growth factor gene with keratoconus in an Australian population. PLoS One 2014; 9: e84067.

60 Kim SH, Mok JW, Kim HS, Joo CK. Association of -31 T $>$ C and $-511 \mathrm{C}>\mathrm{T}$ polymorphisms in the interleukin 1 beta (IL1B) promoter in Korean keratoconus patients. Mol Vis 2008; 14: 2109-2116.

61 Mikami T, Meguro A, Teshigawara T, Takeuchi M, Uemoto R, Kawagoe $\mathrm{T}$ et al. Interleukin 1 beta promoter polymorphism is associated with keratoconus in a Japanese population. Mol Vis 2013; 19: 845-851.

62 Palamar M, Onay H, Ozdemir TR, Arslan E, Egrilmez S, Ozkinay F et al. Relationship between IL1 $\beta-511 C>\mathrm{T}$ and ILRN VNTR polymorphisms and keratoconus. Cornea 2014; 33: $145-147$

63 Chwa M, Atilano SR, Reddy V, Jordan N, Kim DW, Kenney MC. Increased stress-induced generation of reactive oxygen species and apoptosis in human keratoconus fibroblasts. Invest Ophthalmol Vis Sci 2006; 47: 1902-1910.

64 Atilano SR, Coskun P, Chwa M, Jordan N, Reddy V, Le K et al. Accumulation of mitochondrial DNA damage in keratoconus corneas. Invest Ophthalmol Vis Sci 2005; 46: $1256-1263$.

65 Pathak D, Nayak B, Singh M, Sharma N, Tandon R, Sinha R et al. Mitochondrial complex 1 gene analysis in keratoconus. Mol Vis 2011; 17: 1514-1525.

66 Abu-Amero KK, Azad TA, Kalantan H, Sultan T, Al-Muammar AM. Mitochondrial sequence changes in keratoconus patients. Invest Ophthalmol Vis Sci 2014; 55: 1706-1710.

67 Abu-Amero KK, Kondkar AA, Azad TA, Sultan T, Kalantan H, Al-Muammar AM. Keratoconus is associated with increased copy number of mitochondrial DNA. Mol Vis 2014; 20: 1203-1208.

68 Grzybowski A, McGhee C. The early history of keratoconus prior to Nottingham's landmark 1854 treatise on conical cornea: a review. Clin Exp Optom 2013; 96: 140-145.

69 McGhee CN. 2008 Sir Norman McAlister Gregg Lecture: 150 years of practical observations on the conical corneawhat have we learned? Clin Experiment Ophthalmol 2009; 37: 160-176.

70 Malecaze F, Chassaing N, Calvas PGenetics of keratoconusIn:Barbara A(ed) Textbook on Keratoconus New Insights. Jaypee Brothers Medical Publishers: New DelhiNew Delhi, 2012 pp 15. 
71 Mcmonnies CW. Epigenetic mechanisms might help explain environmental contributions to the pathogenesis of keratoconus. Eye Contact Lens 2014; 40: 371-375.

72 Krachmer JH. Eye rubbing can cause keratoconus. Cornea 2004; 23: 539-540.

73 Kenney MC, Brown DJ. The cascade hypothesis of keratoconus. Cont Lens Anterior Eye 2003; 26: 139-146.

74 Cheung IM, McGhee CN, Sherwin T. A new perspective on the pathobiology of keratoconus: interplay of stromal wound healing and reactive species-associated processes. Clin Exp Optom 2013; 96: 188-196.

75 Nelidova D, Sherwin TKeratoconus layer by layer pathology and matrix metalloproteinases In: Rumelt S (ed) Advances in Ophthalmology. InTech: RijekaRijeka, 2012 pp 105-118.

76 Vazirani J, Basu S. Keratoconus: current perspectives. Clin Ophthalmol 2013; 7: 2019-2030.

77 Newsome DA, Gross J, Hassell JR. Human corneal stroma contains three distinct collagens. Invest Ophthalmol Vis Sci 1982; 22: 376-381.

78 Chaerkady R, Shao H, Scott SG, Pandey A, Jun AS, Chakravarti $\mathrm{S}$. The keratoconus corneal proteome: loss of epithelial integrity and stromal degeneration. J Proteomics 2013; 87: 122-131.

79 Polack FM. Contributions of electron microscopy to the study of corneal pathology. Surv Ophthalmol 1976; 20: 375-414.

80 Takahashi A, Nakayasu K, Okisaka S, Kanai A. Quantitative analysis of collagen fiber in keratoconus. Nihon Ganka Gakkai Zasshi 1990; 94: 1068-1073.

81 Akhtar S, Bron AJ, Salvi SM, Hawksworth NR, Tuft SJ, Meek KH. Ultrastructural analysis of collagen fibrils and proteoglycans in keratoconus. Acta Ophthalmol 2008; 86: 764-772.

82 Meek KM, Tuft SJ, Huang Y, Gill PS, Hayes S, Newton RH et al. Changes in collagen orientation and distribution in keratoconus corneas. Invest Ophthalmol Vis Sci 2005; 46: 764-773.

83 Morishige N, Wahlert AJ, Kenney MC, Brown DJ, Kawamoto K, Chikama T et al. Second-harmonic imaging microscopy of normal human and keratoconus. Invest Ophthalmol Vis Sci 2007; 48: 1087-1095.

84 Tuori A, Virtanen I, Aine E, Uusitalo H. The expression of tenascin and fibronectin in keratoconus, scarred and normal human cornea. Graefes Arch Clin Exp Ophthalmol. 1997; 235: 222-229.

85 Määttä M, Heljasvaara R, Sormunen R, Pihlajaniemi T, Autio-Harmainen H, Tervo T. Differential expression of collagen types XVIII/endostatin and XV in normal, keratoconus, and scarred human corneas. Cornea 2006; 25: 341-349.

86 Cheung IM, McGhee CN, Sherwin T. Deficient repair regulatory response to injury in keratoconic stromal cells. Clin Exp Optom 2014; 97: 234-239.

87 Dinarello CA. The interleukin-1 family: 10 years of discovery. FASEB J 1994; 8: 1314-1325.

88 Garlanda C, Dinarello CA, Mantovani A. The interleukin-1 family: back to the future. Immunity 2013; 39: 1003-1018.

89 Girard MT, Matsubara M, Fini ME. Transforming growth factor-beta and interleukin-1 modulate metalloproteinase expression by corneal stromal cells. Invest Ophthalmol Vis Sci 1991; 32: 2441-2454
90 Zhou L, Yue BY, Twining SS, Sugar J, Feder RS. Expression of wound healing and stress-related proteins in keratoconus corneas. Curr Eye Res 1996; 15: 1124-1131.

91 Bauman KA, Wettlaufer SH, Okunishi K, Vannella KM, Stoolman JS, Huang SK et al. The antifibrotic effects of plasminogen activation occur via prostaglandin E2 synthesis in humans and mice. J Clin Invest 2010; 120: 1950-1960.

92 Dogru M, Karakaya H, Ozçetin H, Ertürk H, Yücel A, Ozmen A et al. Tear function and ocular surface changes in keratoconus. Ophthalmology 2003; 110: 1110-1118.

93 Pannebaker C, Chandler HL, Nichols JJ. Tear proteomics in keratoconus. Mol vis 2010; 16: 1949-1957.

94 Seppälä HP, Määttä M, Rautia M, Mackiewicz Z, Tuisku I, Tervo T et al. EMMPRIN and MMP-1 in keratoconus. Cornea 2006; 25: 325-330.

95 Balasubramanian SA, Wasinger VC, Pye DC, Willcox MD. Preliminary identification of differentially expressed tear proteins in keratoconus. Mol Vis 2013; 19: 2124-2134.

96 Acera A, Vecino E, Rodríguez-Agirretxe I, Aloria K, Arizmendi JM, Morales C et al. Changes in tear protein profile in keratoconus disease. Eye (Lond) 2011; 25: 1225-1233.

97 Domsalla A, Melzig MF. Occurrence and properties of proteases in plant latices. Planta Med 2008; 74: 699-711.

98 Ha M, Bekhit Ael-D, Carne A, Hopkins DL. Characterisation of commercial papain, bromelain, actinidin and zingibain protease preparations and their activities toward meat proteins. Food Chem 2012; 134: 95-105.

99 Abrahamson M, Alvarez-Fernandez M, Nathanson CM. Cystatins. Biochem Soc Symp 2003; 70: 179-199.

100 Im E, Kazlauskas A. The role of cathepsins in ocular physiology and pathology. Exp Eye Res 2007; 84: 383-388.

101 Sherwin T, Brookes NH, Loh IP, Poole CA, Clover GM Cellular incursion into Bowman's membrane in the peripheral cone of the keratoconic cornea. Exp Eye Res 2002; 74: $473-482$

102 Maertzdorf J, Osterhaus AD, Verjans GM. IL-17 expression in human herpetic stromal keratitis: modulatory effects on chemokine production by corneal fibroblasts. J Immunol 2002; 169: 5897-5903.

103 Jun AS, Cope L, Speck C, Feng X, Lee S, Meng H et al. Subnormal cytokine profile in the tear fluid of keratoconus patients. PLoS One 2011; 6: 1-8.

104 Karaca EE, Özmen MC, Ekici F, Yüksel E, Türkoğlu Z. Neutrophil-to-lymphocyte ratio may predict progression in patients with keratoconus. Cornea 2014; 33: 1168-1173.

105 Kolozsvári BL, Berta A, Petrovski G, Miháltz K, Gogolák P, Rajnavölgyi $\mathrm{E}$ et al. Alterations of tear mediators in patients with keratoconus after corneal crosslinking associate with corneal changes. PLoS One 2013; 8: e76333.

106 Wojcik KA, Blasiak J, Szaflik J, Szaflik JP. Role of biochemical factors in the pathogenesis of keratoconus. Acta Biochim Pol 2014; 61: 55-62.

107 Kolozsvári BL, Petrovski G, Gogolák P, Rajnavölgyi É, Tóth F, Berta A et al. Association between mediators in the tear fluid and the severity of keratoconus. Ophthalmic Res 2014; 51: 46-51.

108 Balasubramanian SA, Pye DC, Willcox MD. Levels of lactoferrin, secretory $\operatorname{IgA}$ and serum albumin in the tear film of people with keratoconus. Exp Eye Res 2012; 96: 132-137. 
109 Ben Mkaddem S, Rossato E, Heming N, Monteiro RC. Anti-inflammatory role of the IgA Fc receptor (CD89): from autoimmunity to therapeutic perspectives. Autoimmun Rev 2013; 12: 666-669.

110 González-Chávez SA, Arévalo-Gallegos S, Rascón-Cruz Q. Lactoferrin: structure, function and applications. Int J Antimicrob Agents 2009; 33: 301-308.

111 Coyle JT. Keratoconus and eye rubbing. Am J Ophthalmol 1984; 97: 527-528

112 McMonnies CW. Abnormal rubbing and keratectasia. Eye Contact Lens 2007; 33: 265-271.

113 McMonnies CW. Mechanisms of rubbing-related corneal trauma in keratoconus. Cornea 2009; 28: 607-615.

114 Shneor E, Millodot M, Blumberg S, Ortenberg I, Behrman S, Gordon-Shaag A. Characteristics of 244 patients with keratoconus seen in an optometric contact lens practice. Clin Exp Optom 2013; 96: 219-224.

115 Ridley F. Eye-rubbing and contact lenses. Br J Ophthalmol 1961; 45: 631.

116 Karseras AG, Ruben M. Aetiology of keratoconus. Br J Ophthalmol 1976; 60: 522-525.

117 Jafri B, Lichter H, Stulting RD. Asymmetric keratoconus attributed to eye rubbing. Cornea 2004; 23: 560-564.

118 Malecaze F, Ancele E, Butterworth JEpidemiology of keratoconusIn:Barbara A(ed) Textbook on Keratoconus New Insights. Jaypee Brothers Medical Publishers: New DelhiNew Delhi, 2012 pp 5.

119 McMonnies CW, Korb DR, Blackie CA. The role of heat in rubbing and massage-related corneal deformation. Cont Lens Anterior Eye 2012; 35: 148-154.

120 Balasubramanian SA, Pye DC, Willcox MD. Effects of eye rubbing on the levels of protease, protease activity and cytokines in tears: relevance in keratoconus. Clin Exp Optom 2013; 96: 214-218.

121 Dursun D, Piniella AM, Pflugfelder SC. Pseudokeratoconus caused by rosacea. Cornea 2001; 20: 668-669.

122 Stoesser F, Lévy D, Moalic S, Colin J. Pseudokeratoconus and ocular rosacea. J Fr Ophtalmol 2004; 27: 278-284.

123 Afonso AA, Sobrin L, Monroy DC, Selzer M, Lokeshwar B, Pflugfelder SC. Tear fluid gelatinase B activity correlates with IL-1alpha concentration and fluorescein clearance in ocular rosacea. Invest Ophthalmol Vis Sci 1999; 40: 2506-2512.

124 Kao WW, Vergnes JP, Ebert J, Sundar-Raj CV, Brown SI. Increased collagenase and gelatinase activities in keratoconus. Biochem Biophys Res Commun 1982; 107: 929-936.

125 Balasubramanian SA, Pye DC, Willcox MD. Are proteinases the reason for keratoconus? Curr Eye Res 2010; 35: 185-191.

126 Smith VA, Easty DL. Matrix metalloproteinase 2: involvement in keratoconus. Eur J Ophthalmol 2000; 10: 215-226.

127 Smith VA, El-Rakhawy A, Easty DL. Matrix metalloproteinase-2 activation in cultured corneas. Ophthalmic Res 2001; 33: 1-6.

128 Smith VA, Hoh HB, Littleton M, Easty DL. Over-expression of a gelatinase A activity in keratoconus. Eye (Lond) 1995; 9 : 429-433.

129 Clark IM, Swingler TE, Sampieri CL, Edwards DR. The regulation of matrix metalloproteinases and their inhibitors. Int J Biochem Cell Biol 2008; 40: 1362-1378.

130 Kusano K, Miyaura C, Inada M, Tamura T, Ito A, Nagase H et al. Regulation of matrix metalloproteinases (MMP-2, -3, -9 , and -13 ) by interleukin-1 and interleukin- 6 in mouse calvaria: association of MMP induction with bone resorption. Endocrinology 1998; 139: 1338-1345.

131 Piperi C, Papavassiliou AG. Molecular mechanisms regulating matrix metalloproteinases. Curr Top Med Chem 2012; 12: 1095-1112.

132 Abalain JH, Dossou H, Colin J, Floch HH. Levels of collagen degradation products (telopeptides) in the tear film of patients with keratoconus. Cornea 2000; 19: 474-476.

133 Bilgihan K, Hondur A, Sul S, Ozturk S. Pregnancy-induced progression of keratoconus. Cornea 2011; 30: 991-994.

134 Sherwood OD. Relaxin's physiological roles and other diverse actions. Endocr Rev 2004; 25: 205-234.

135 Spoerl E, Zubaty V, Raiskup-Wolf F, Pillunat LE. Oestrogen-induced changes in biomechanics in the cornea as a possible reason for keratectasia. Br J Ophthalmol 2007; 91: 1547-1550.

136 Sethi A, Wordinger RJ, Clark AF. Focus on molecules: lysyl oxidase. Exp Eye Res 2012; 104: 97-98.

137 Bykhovskaya Y, Li X, Epifantseva I, Haritunians T, Siscovick D, Aldave A et al. Variation in the lysyl oxidase (LOX) gene is associated with keratoconus in family-based and case-control studies. Invest Ophthalmol Vis Sci 2012; 53: 4152-4157.

138 Hasanian-Langroudi F, Saravani R, Validad MH, Bahari G, Yari D. Association of Lysyl oxidase (LOX) polymorphisms with the risk of Keratoconus in an Iranian population. Ophthalmic Genet 2014; e-pub ahead of print 6 February 2014.

139 Dudakova L, Jirsova K. The impairment of lysyl oxidase in keratoconus and in keratoconus-associated disorders. J Neural Transm 2013; 120: 977-982.

140 Dudakova L, Liskova P, Trojek T, Palos M, Kalasova S, Jirsova K. Changes in lysyl oxidase (LOX) distribution and its decreased activity in keratoconus corneas. Exp Eye Res 2012; 104: 74-81.

141 Avetisov SE, Mamikonian VR, Novikov IA. [The role of tear acidity and $\mathrm{Cu}$-cofactor of lysyl oxidase activity in the pathogenesis of keratoconus]. Vestn Oftalmol 2011; 127: 3-8.

142 Shoham A, Hadziahmetovic M, Dunaief JL, Mydlarski MB, Schipper HM. Oxidative stress in diseases of the human cornea. Free Radic Biol Med 2008; 45: 1047-1055.

143 Arnal E, Peris-Martínez C, Menezo JL, Johnsen-Soriano S, Romero FJ. Oxidative stress in keratoconus? Invest Ophthalmol Vis Sci 2011; 52: 8592-8597.

144 Wojcik KA, Kaminska A, Blasiak J, Szaflik J, Szaflik JP. Oxidative stress in the pathogenesis of keratoconus and Fuchs endothelial corneal dystrophy. Int J Mol Sci 2013; 14: 19294-19308.

145 Toprak I, Kucukatay V, Yildirim C, Kilic-Toprak E, Kilic-Erkek O. Increased systemic oxidative stress in patients with keratoconus. Eye (Lond) 2014; 28: 285-289.

146 Buddi R, Lin B, Atilano SR, Zorapapel NC, Kenney MC, Brown DJ. Evidence of oxidative stress in human corneal diseases. J Histochem Cytochem 2002; 50: 341-351.

147 Olofsson EM, Marklund SL, Pedrosa-Domellöf F, Behndig A. Interleukin-1alpha downregulates extracellularsuperoxide dismutase in human corneal keratoconus stromal cells. Mol Vis 2007; 13: 1285-1290.

148 Becquet F, Courtois Y, Goureau O. Nitric oxide in the eye: multifaceted roles and diverse outcomes. Surv Ophthalmol 1997; 42: 71-82.

149 Brown DJ, Lin B, Chwa M, Atilano SR, Kim DW, Kenney MC. Elements of the nitric oxide pathway can 
degrade TIMP-1 and increase gelatinase activity. Mol Vis 2004; 10: 281-288.

150 Cheung IM, McGhee CN, Sherwin T. Beneficial effect of the antioxidant riboflavin on gene expression of extracellular matrix elements, antioxidants and oxidases in keratoconic stromal cells. Clin Exp Optom 2014; 97: 349-355.

151 Kim WJ, Rabinowitz YS, Meisler DM, Wilson SE. Keratocyte apoptosis associated with keratoconus. Exp Eye Res 1999; 69: 475-481.

152 Wilson SE, He YG, Weng J, Li Q, McDowall AW, Vital M et al. Epithelial injury induces keratocyte apoptosis: hypothesized role for the interleukin-1 system in the modulation of corneal tissue organization and wound Healing. Exp Eye Res 1996; 62: 325-327.

153 Fini ME, Strissel KJ, Girard MT, Mays JW, Rinehart WB. Interleukin 1 alpha mediates collagenase synthesis stimulated by phorbol 12-myristate 13-acetate. J Biol Chem 1994; 269(15): 11291-11298.

154 Planck SR, Huang XN, Robertson JE, Rosenbaum JT. Cytokine mRNA levels in rat ocular tissues following systemic endotoxin treatment. Invest Ophthalmol Vis Sci 1994; 35: 924-930.

155 Weng J, Mohan RR, Li Q, Wilson SE. IL-1 upregulates keratinocyte growth factor and hepatocyte growth factor mRNA and protein production by cultured stromal fibroblast cells: interleukin-1 beta expression in the cornea. Cornea 1997; 16: 465-471.

156 Chwa M, Atilano SR, Hertzog D, Zheng H, Langberg J, Kim DW et al. Hypersensitive response to oxidative stress in keratoconus corneal fibroblasts. Invest Ophthalmol Vis Sci 2008; 49: 4361-4370.

157 Brown DJ, Chwa M, Opbroek AJ, Kenney MC. Altered gelatinolytic activities in an apparent unilateral keratoconus patient. A case report. Cornea 1994; 13: 108-113.

158 Kenney MC, Chwa M, Opbroek AJ, Brown DJ. Increased gelatinolytic activity in keratoconus keratocyte cultures. A correlation to an altered matrix metalloproteinase-2/ tissue inhibitor of metalloproteinase ratio. Cornea 1994; 13: 114-124.

159 Matthews FJ, Cook SD, Majid MA, Dick AD, Smith VA. Changes in the balance of the tissue inhibitor of matrix metalloproteinases (TIMPs)-1 and -3 may promote keratocyte apoptosis in keratoconus. Exp Eye Res 2007; 84: 1125-1134.
160 Joseph R, Srivastava OP, Pfister RR. Downregulation of $\beta$-actin gene and human antigen $\mathrm{R}$ in human keratoconus. Invest Ophthalmol Vis Sci 2012; 53: 4032-4041.

161 Kenney MC, Chwa M, Lin B, Huang GH, Ljubimov AV, Brown DJ. Identification of cell types in human diseased corneas. Cornea 2001; 20: 309-316.

162 Kuffová L, Holán V, Lumsden L, Forrester JV, Filipec M. Cell subpopulations in failed human corneal grafts. Br J Ophthalmol 1999; 83: 1364-1369.

163 Mathew JH, Goosey JD, Burns AR, Bergmanson JPG. Immunohistochemistry and ultrastructure of anterior stromal cells in keratoconus. Invest Ophthalmol Vis Sci 2010; 51, E-Abstract 6230-D795.

164 Sykakis E, Carley F, Irion L, Denton J, Hillarby MC. An in depth analysis of histopathological characteristics found in keratoconus. Pathology 2012; 44: 234-239.

165 Solomon AInflammation in the pathogenesis of keratoconusIn:Barbara A(ed) Textbook on Keratoconus New Insights. Jaypee Brothers Medical Publishers: New DelhiNew Delhi, 2012 pp 18-22.

166 Fermor B, Weinberg JB, Pisetsky DS, Misukonis MA, Banes AJ, Guilak F. The effects of static and intermittent compression on nitric oxide production in articular cartilage explants. J Orthop Res 2001; 19: 729-737.

167 Attur MG, Dave M, Akamatsu M, Katoh M, Amin AR. Osteoarthritis or osteoarthrosis: the definition of inflammation becomes a semantic issue in the genomic era of molecular medicine. Osteoarthritis Cartilage 2002; 10: 1-4 Erratum in: Osteoarthritis Cartilage. 2003; 11(9): 706.

168 Pelletier JP, Martel-Pelletier J, Abramson SB. Osteoarthritis, an inflammatory disease: potential implication for the selection of new therapeutic targets. Arthritis Rheum 2001; 44: 1237-1247.

169 Daghestani HN, Pieper CF, Kraus VB. Soluble macrophage biomarkers indicate inflammatory phenotypes in patients with knee osteoarthritis. Arthritis Rheumatol 2015; 67: 956-965.

170 Suarez-Cortes TM, Soria J, Acera A, Gonzalez N, Iloro I, Elortza F et al. Human tear peptide/protein profiling study of keratoconus grades by SPE-MALDI-TOF mass spectrometry analyses. Invest Ophthalmol Vis Sci 2014; 55, E-Abstract 2006. 2014 ARVO 2006-B0305. 